\title{
The Role of Human Capital Factors on Poverty in Informal Settlement: Informal Settlement of Sheikh-Hasan, Mashhad City, Iran
}

\author{
Javad Barati ${ }^{1}$, Sahar Soltani ${ }^{2}$, Simin Froogh-Zadeh ${ }^{2} \&$ Farzaneh Razaghian $^{2}$ \\ ${ }^{1}$ Iranian Academic Center for Education Culture \& Research (ACECR), Khorasan Razavi Branch, Iran \\ ${ }^{2}$ Academic staff of Iranian Academic Center for Education Culture \& Research (ACECR), Khorasan Razavi \\ Branch, Iran \\ Correspondence: Sahar Soltani, Academic staff of Iranian Academic Center for Education Culture \& Research \\ (ACECR), Khorasan Razavi Branch, Iran. Tel: 98-051-3876-2000. E-mail: soltani.sahar@hotmail.com
}

Received: April 4, $2017 \quad$ Accepted: May 11, $2017 \quad$ Online Published: July 30, 2017

doi:10.5539/jsd.v10n4p22 URL: https://doi.org/10.5539/jsd.v10n4p22

This paper is derived from the research project by Iranian academic center for education culture \& research (ACECR), workgroup of informal settlement.

\begin{abstract}
This paper investigates the determinants of multi-dimension poverty in informal settlements of Mashhad City. It specially analyzes human capital factors, among factors that influence poverty level. Education, skills, experience and knowledge have important role in promoting income level and in access to sustainable jobs, especially in informal settlements that have lower human capital level than the urban areas other. Mashhad city has most marginal settlements in Iran. Sheikh-Hasan Neighborhood in Mashhad Municipality region 4 has been selected as case study. This study is based on information gathered from household level in 2016 and the ordered logit model is employed to estimate factors influencing urban poverty. Data were obtained from 300 households using the questionnaire Through the Systematic Random technique. Calculation of poverty indexes reveals that nearly $87 \%$ of households are below absolute poverty line and $20 \%$ of households are below extreme poverty line. Marginal effects show variables of "job stability", "Ownership", "Household size" and "Education of household head" have the greatest impact on poverty alleviation. Also, variables of "Education level" and "highest level of education of household members" have positive effect and significant on poverty. Results represent that poverty in informal settlements of Mashhad is strongly linked to factors such as human capital. In addition, with increasing the level of knowledge of household heads and creation of favorable conditions for increasing of the education level of household members can reduce poverty.
\end{abstract}

Keywords: urban poverty, ordered logit model, informal settlement, Mashhad

\section{Introduction}

\subsection{Introduce the Problem}

Investment in human capital, as one of most affect tools for improvement of social welfare, has positive relationship with income. Different definitions have expressed for human capital that contains a component of the skills, education, training and health consider for capital of individuals. These empower individuals to product more qualitative output or to serve better and more services. Personal characters (that include knowledge, skills and experience) raise possibilities for earning more money income. Therefore, these characters are called human capital (Sarwar Awan et. al., 2011) and have positive effect on economic growth and per-capita income, according to Endogenous Growth Model. But the effect is not the same in various regions or may to differ in scale of impacts in the regions.

The urban regions, especially informal settlements, are important for regional and national planers and policy-makers to raise per-capita income of poor households in the areas. Relationship between human capital and income is very important for cities with more inequality and poor regions. These regions are important for metropolises with vast informal settlements. In Iran, Mashhad City has most population located in informal settlements that include one-third of whole urban resident. About 1.2 million people of resident in Mashhad live in informal settlements and suffering from poverty. Despite the importance of urban poverty in informal 
settlements of Mashhad, few studies have been done in Mashhad, specially.

\subsection{Explore Importance of the Problem}

In Iran, many studies have been investigated informal settlements and have been concluded education have been correspond urban poverty. But no study has examined especially effect of human capital on urban poverty, however the studies related to informal settlements, consider an important role for human capital (naghdi, 2010; Banifatemeh, 2012; Oliaei, 2011, Taghdisi et. al., 2012). The effect of human capital on urban poverty is important in the city of Mashhad, Because of informal settlements issue in this city and impact on employment and income. This study selects the Sheikh-Hasan neighborhood as case study and survey effect of human capital on urban poverty in this urban neighborhood that is one of vast informal settlements located in municipality district 4 .

This article is organized as follows: After the introduction and in the next section represent Literature Review. Then, it introduces Materials and Methods, which is included Study case, Model introducing and data. Fourth section is dedicated to empirical results, and in the end is presented, conclusions.

\subsection{Describe Relevant Scholarship}

Here experimental studies considered in two categories: studies focused on poverty line in the Khorasan Razavi province and studies focused on effect of human capital on poverty due to discrete regression methods. The classification is done so that a wide range of studies have been done on urban poverty.

Salari (2016) calculating the poverty lines 8 provinces of Iran (Razavi Khorasan, North Khorasan, South Khorasan, Golestan, Semanan, Yazad, Kerman, Sistan and Baluchestan) based on the inverse of the Engel coefficient. The results showed that Razavi Khorasan after South Khorasan had the largest increase in poverty level during 2002 to 2013. The absolute poverty threshold in Razavi Khorasan has been achieved 6.212 million toman per year for 2013. Heidari and sami (2012) investigated poverty line in Razavi Khorasan during 1991 to 2010. They applied seemingly unrelated regression equations (SURE) to estimate poverty line. The result showed the poverty line in this province was 5.265 million toman per year for 2011. Rashidi and Naji- Rashidi and Meidani (2013) have been achieved 6.9076 million toman per year for Razavi Khorasan poverty line in 2012. By adjusting household expenditure based on regional inflation not find Significant differences between results. Although any study has used different way for determining poverty line.

The impact of human capital on poverty has been done in different countries such as Pakistan, Ghana, Mozambique and India which they are among the countries with the highest urban poverty in world. Most of these studies applied discrete regression methods for the determinants of urban poverty. Rolleston (2009) explored relationships between education and household welfare for Ghana by probit and logit model. Positive relation between higher access to basic education and poverty level was one of the research key results. The results suggest that education levels play an important role in determining household welfare. Handa et al. (2004) by ordered probit method evaluated role of education in determining the social well-being of Mozambican households. They demonstrate that education play a powerful determinant of economic and social well-being, also impact of mother's education is especially strong. Sarwar Awan et al. (2011) surveyed impact of human capital on urban poverty in Sargodha City, Pakistan. They with survey-based analysis was carried out on a sample of 330 households and resulted that education and experience is negatively related with urban poverty. Binomial logistic regression used for estimating the impact of human capital variables on poverty. In the dependent variable (poverty) 0 when a household is not poor and 1 when is poor. Pakistan is among the countries with the most informal settlements in the world. Ali and Ahmad (2013) assess impact of human capital in poverty alleviation for 34 districts of Punjab province in Pakistan. They resulted human capital (knowledge, training and skills) had positive impact on poverty reduction and productivity increase of the workers. Ullah Khan et al. (2016) explores the role of human capital in mitigating the through of poverty dilemma in the Khyber Pakhtunkhwa province of Pakistan. Data gathered though the questionnaire with sample of 150 households. Logistic regression model been used to explore the variety of human capital factors on poverty. They resulted that technical training and education are the important factors for eliminating poverty.

\section{Method}

\subsection{Identify Subsections}

The Sheikh-Hasan neighborhood is located in district 4 of Mashhad (Note 1) municipality. The total neighborhood area is 1.248 square kilometers. On October 2011, total population of the neighborhood is 41.9 thousand (10480 households) that is 29 percent of the total district population and 4.5 percent of the total informal settlements population of Mashhad (Note 2). The literacy rate of the Sheikh-Hasan neighborhood is 86 
percent whereas the 89 percent for the males and 84 percent for the females. (Note 3) In 2016, there are 55 schools (inclusive high-school, primary school, Secondary and Vocational Education and Training) and no any university or education institute in the neighborhood. Also no library is in the neighborhood (Table 1). District 4 of municipality has the most poor neighborhoods and informal settlements in Mashhad.

Table 1. Comparison of and training features and educational facilities in district 4 of Mashhad municipality with whole-city of Mashhad

\begin{tabular}{|c|c|c|c|c|c|c|c|c|}
\hline area & $\begin{array}{l}\text { Population } \\
\text { (1000 } \\
\text { people) }\end{array}$ & $\begin{array}{l}\text { Literacy } \\
\text { rates } \\
\text { (percent) }\end{array}$ & $\begin{array}{l}\text { Universities and } \\
\text { Institutes of } \\
\text { Higher } \\
\text { Education }\end{array}$ & $\begin{array}{l}\text { Public } \\
\text { libraries }\end{array}$ & $\begin{array}{l}\text { Schools } \\
\text { (per } 1000 \\
\text { student) }\end{array}$ & $\begin{array}{l}\text { Classes in } \\
\text { Schools } \\
\text { (per } 1000 \\
\text { student) }\end{array}$ & $\begin{array}{l}\text { Higher } \\
\text { educated } \\
\text { population } \\
\text { (percent) }\end{array}$ & $\begin{array}{c}\text { Cultural-Social } \\
\text { centers }\end{array}$ \\
\hline $\begin{array}{l}\text { district } 4 \text { of } \\
\text { municipality }\end{array}$ & 216.8 & 87.5 & 0 & 2 & 3.59 & 37.8 & 4 & $\begin{array}{c}1 \text { (neighborhood } \\
\text { of Panjtan) }\end{array}$ \\
\hline Mashhad & 2507.5 & 91.8 & 22 & 45 & 4.19 & 40.6 & 16 & 22 \\
\hline
\end{tabular}

Source: Statistical yearbook of the Mashhad 2014, National Census of Population and Housing 2011, Statistical Yearbook of Education 2015

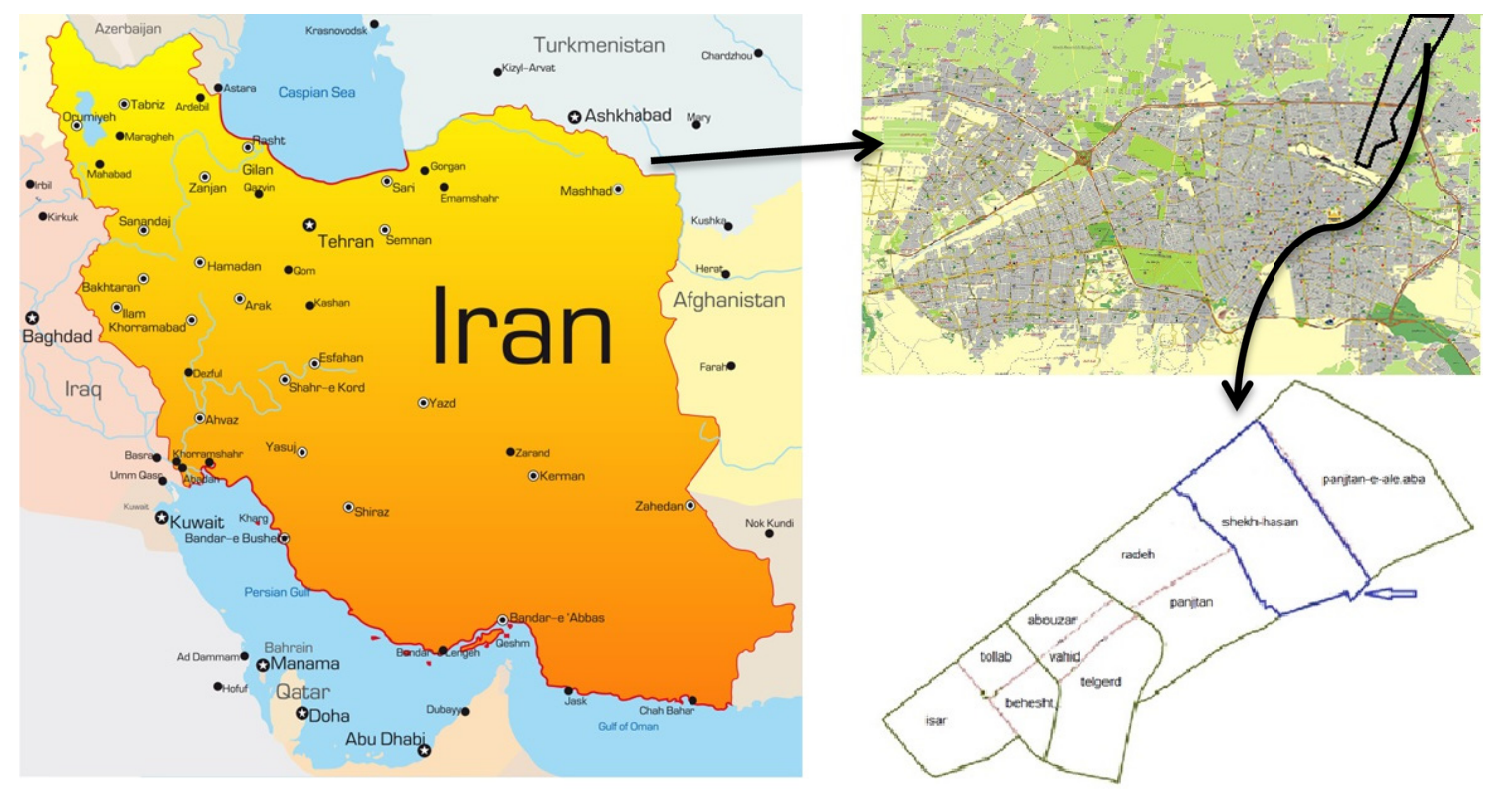

Figure 1. Position of Shekh-Hasan neighborhood in in district 4 of Mashhad municipality, Iran

Research computation implement in two phases. First, extreme, absolute and Relative poverty lines calculate for Mashhad City. Poverty line determine by various method which in this study extreme poverty line calculates by using 2300 Calories per person per day (FEI approach) and is synonymous with food poverty. Absolute poverty calculates by using Orshansky method. Also Relative poverty line determine according to 66 percent of total expenditure. Then, impact of human capital on poverty level in case study survey by Multidimensional Analysis. Ordered logistic model is suitable for it.

Iran Institute of Nutrition expresses caloric requirements and goods required weight which use in poverty level measurement. Then cost of consumption per adult equivalent is considered for all commodity categories (Dercon and Krishnan, 1998). Food poverty line is determined by use these data and is applied for measurement of absolute poverty line and calculation of non-food needs. Absolute poverty line according to Orshansky method is base of food costs which achieving multiplied by the inverse of the portion of total expenditure on food expenditure. Relative poverty line is 66 percent of average total expenditure per person. Achieving Poverty level inclusive food and non-food needs and represents multi-dimension poverty. The follow table show caloric 
requirements, weight and price for each item.

Table 2. Calorics, weight and price for food items

\begin{tabular}{ccccc}
\hline food items & price food basket (toman) & Price per kilo (toman) & Calorie & Weight (gram) \\
\hline bread & 750 & 3000 & 689 & 250 \\
rice & 800 & 8000 & 360 & 100 \\
beans & 270 & 9000 & 106 & 30 \\
sugar & 202.5 & 4500 & 180 & 45 \\
oil & 200 & 5000 & 225 & 40 \\
meat & 700 & 35000 & 87.6 & 20 \\
chicken & 162.5 & 6500 & 73.2 & 25 \\
fish & 300 & 15000 & 25.7 & 20 \\
egg & 100 & 4000 & 40 & 25 \\
milk & 150 & 1500 & 64 & 100 \\
yogurt & 250 & 2500 & 83.7 & 100 \\
cheese & 160 & 8000 & 49 & 20 \\
vegetable & 800 & 2500 & 116.2 & 320 \\
fruit & 1225 & 3500 & 195 & 350 \\
daily calories & - & - & 2294.4 & - \\
\hline
\end{tabular}

Source: calculation in this research

In second step, ordered logistic regression used to estimate influence various factors on poverty level. Achieved Poverty thresholds in first step set as dependent variable. It divided to four categories consist of individuals with income lower than extreme poverty line, between extreme and absolute poverty line, between absolute and relative poverty line and upper than relative poverty line. The explanatory variables are consisting of household, head of household characteristics, and the education level and job-related skills of household members. However dependent variable is ordinal, explanatory variables are both discrete and continuous. Below equation represent ordered response model:

$$
Y_{i}^{*}=\dot{\beta} X_{i}+\varepsilon_{i}
$$

Where $Y_{i}{ }^{*}$ represents households in comparison with poverty levels and $X_{i}$ is a vector of independent explanatory variables. Since the continuous latent variable $\mathrm{Y}_{\mathrm{i}}{ }^{*}$ cannot be observed, instead of $\mathrm{Y}_{\mathrm{i}}{ }^{*}$ the following is observed:

$$
\begin{array}{ll}
\mathrm{y}=1 \text { if } & \mu_{0} \leq \mathrm{y}^{*}<\mu_{1} \\
\mathrm{y}=2 \text { if } & \mu_{1} \leq \mathrm{y}^{*}<\mu_{2} \\
\mathrm{y}=3 \text { if } & \mu_{2} \leq \mathrm{y}^{*}<\mu_{3} \\
\vdots & \\
\mathrm{y}=\mathrm{J} \text { if } & \mu_{\mathrm{j}-1} \leq \mathrm{y}^{*}
\end{array}
$$

Where ordered categorical variable $\left(\mathrm{Y}_{\mathrm{i}}\right)$ ranked into 4 categories (1 for households with income lower than extreme, 2 for households with income between extreme and absolute poverty line, 3 for households with income between absolute and relative poverty line and 4 for households with income upper than relative poverty line), $\mu$ is a vector of parameters estimated with the $\beta$. Cumulative distribution function of $\varepsilon$ (disturbance term) is as follows:

$$
F(\varepsilon)=\frac{\exp (\varepsilon)}{1-\exp (\varepsilon)}=\frac{1}{1-\exp (-\varepsilon)}
$$

Probability of observing an outcome is used to derive maximum likelihood estimates of $\beta$ and $\mu$ (Wooldridge, 2002): 


$$
\operatorname{Pr}\left[y_{i}=\mathrm{j}\right]=\frac{1}{1+e^{-u_{j}+\beta x_{i}}}-\frac{1}{1+e^{-u_{j-1}+\beta x_{i}}}
$$

\subsection{Data}

Questionnaire used to gathering the data collection of household inclusive expenditure, income, job characteristics, house characteristics and individual characteristics. The explanatory variables include work experience, the level of education of household head, highest level of education of family members, expenditure on education, family size and job skills (Note 4). Statistical population consisted of the residents of The Sheikh-Hasan neighborhood and sampling method is simple random. The Cochran's formula is used for calculating sample size. Accordingly, the sample size of 300 is obtained and the questionnaire completed by women and mothers. Women have more detailed information of their home expenditure and are more accessible.

\subsection{Descriptive Analysis}

The study is to distinguish between extreme poverty and absolute poverty. Minimum food needs in 2016 is equal to 182 million rials which is introduced as extreme poverty. Absolute poverty threshold is based on basic human needs, including food, sanitation facilities, health, shelter, education and information. Relative poverty differs between countries and defines 66 per-cent of expenditure average or Middle. Annual Absolute and relative poverty lines for household are equal to 182 and 195 million rials, respectively.

Table (3) illustrates extreme, absolute and relative poverty lines and household's characteristics in area of study. In the neighborhood of Sheikh-Hassan, annual expenditure of household to meet minimum food needs is equal to 102 million rials and 20 per-cent households spend less than the amount. The households with annual income more than 182 million rials are 87 per-cent total households in the neighborhood.

Table 3. Poverty line per person in 2016 (million rials)

\begin{tabular}{lccc}
\hline poverty line & Extreme poverty & Absolute poverty & relative poverty \\
\hline person per year (rial) & 21852000 & 38917240 & 41658430 \\
household per year (rial) & 102410866 & 182388280 & 195235000 \\
share of households below poverty line (\%) & 20 & 87 & 89
\end{tabular}

* The household dimension or size in the neighborhood is 4.7 while household size in Mashhad City is equal to 3.5 , in 2011. The relative poverty line has calculated in Mashhad and taking into account household size in Mashhad.

Source: calculation in this research

In respect of the above defined thresholds for poverty, the poverty variable as the dependent variable including the four categories (Note 5).

\section{Results}

The signs of the coefficients of logit and probit models are directly interpretable, but not the magnitudes. Thus, marginal effects used to interpret coefficients (Bohn Nielsen, 2005). This study uses order logit estimator to calculate marginal effects and to analyze the impact of human capital on poverty. Maximum likelihood estimation $(M L E)$ shows the significance of the model. According to the results, Education level, experience and skill are the most important components of human capital and they affect poverty. Also, they have very much effective on job stability. However job stability may affect poverty level. Result shows that the education and age of head of household have significant effect on poverty alleviation. Also, variables of job stability, household size and highest level of education of family members have significant effect on poverty. Against, experience and skill are not significant. Low level of skill among residents and notable number of the retired in the region, which are receive minimum wage on base labor Law, are its reason. As can be seen from the table (3), the majority of households ( 87 per-cents) are below the absolute poverty line which represents the minimum income level for the households.

Education head of household has positive effect on poverty alleviation and also has a high significance level. Education head of household directly affect job kind and skill and indirect effect on per-capita income households through a household smaller size. Household size has a significant negative impact on the poverty and households with smaller size will be per capita income higher. 
The other important variables are job stability and highest level of education in household members. Both of these variables have significant positive effect but job stability is greater significance. In fact, households with higher incomes have greater durability of job and they less have changed their jobs.

Table 4. Results of ordered logistic regression to determine signs of the coefficients

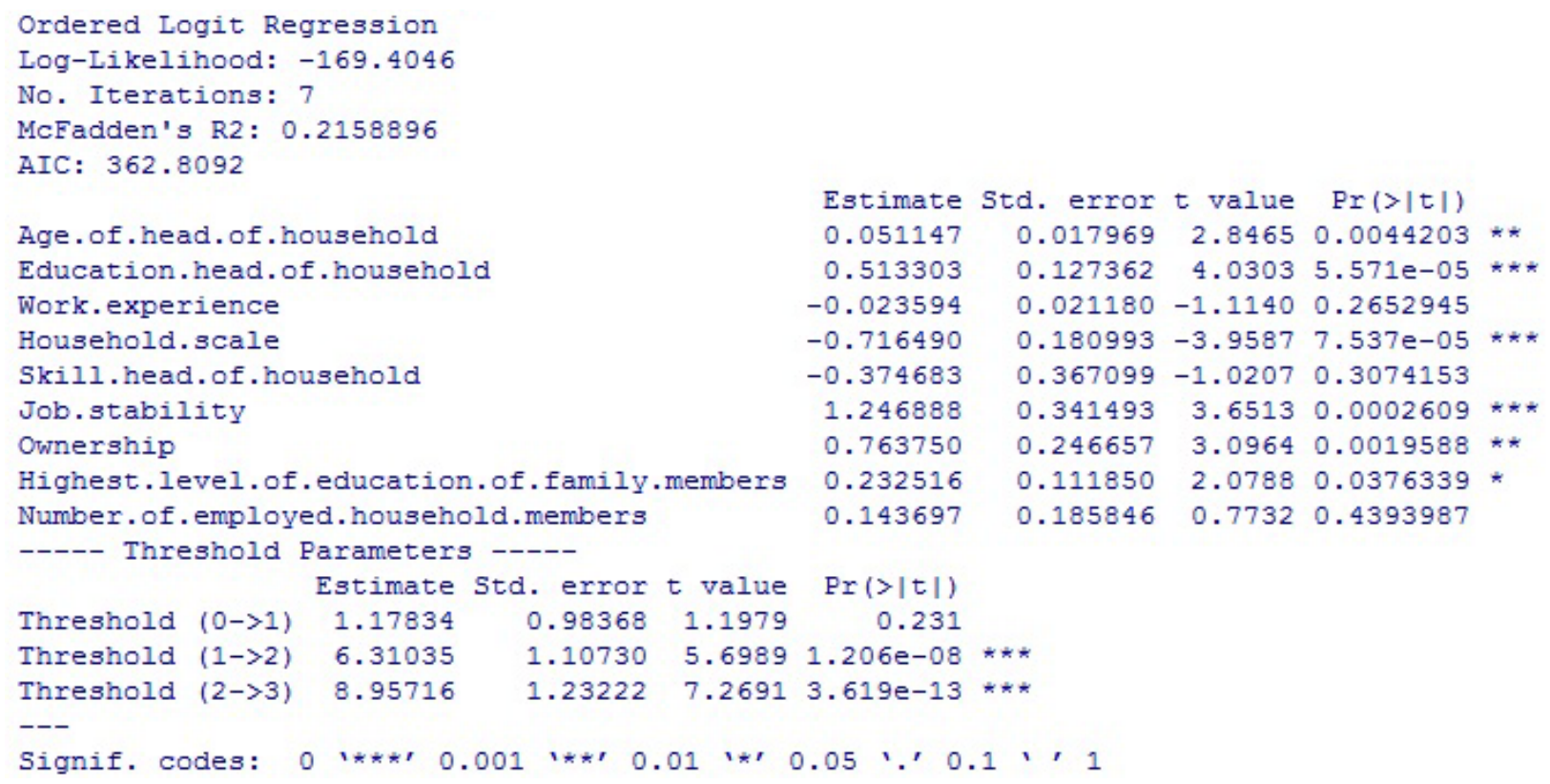

Source: calculation in this research

Marginal effects in discrete models measure discrete change or instantaneous rate of change (Depending on discrete or continuous independent variable). These effects show the difference in the predicted probabilities in one category relative to the other category. According to table (5), with increasing age of household head, the chance that household to be moved from the first category to the second category (from below extreme poverty to upper) increase 0.018 percent and the chance that household to be moved from the first category to the second and third categories increase 0.3 and 0.026 percent, respectively. Also, with increasing age of household head, the chance that household to be in the first category decreases 0.34 percent. As a result, the increase in age of household head, the probability out of the first category is very high.

Rising Education of household head increases the chance switching household to the third and the fourth categories, respectively 3 and 0.26 percent. Also, the household chance for sit in the first category decreases 3.49 percent. Comparison of marginal effects show variables of "job stability", "Ownership", "Household size" and "Education of household head" have the greatest impact on increasing welfare and reducing poverty levels household. These variables have the highest impact coefficient and the probability of poverty alleviation, as the household chance for switching from the first category to the second category is 7.38, 4.52, 4.24 and 3 percent respectively. 
Table 5. Marginal effects for each category of the poverty level

\begin{tabular}{|c|c|c|c|c|}
\hline & $\begin{array}{l}\text { marginal effects of first } \\
\text { category (below extreme } \\
\text { poverty) }\end{array}$ & $\begin{array}{l}\text { marginal effects of second } \\
\text { category (between extreme } \\
\text { poverty and absolute } \\
\text { poverty) }\end{array}$ & $\begin{array}{l}\text { marginal effects of third } \\
\text { category (between absolute } \\
\text { poverty and relative } \\
\text { poverty) }\end{array}$ & $\begin{array}{l}\text { marginal effects of } \\
\text { fourth category (upper } \\
\text { relative poverty) }\end{array}$ \\
\hline Age.of.head.of.household & -0.0034847 & $1.8855 \mathrm{e}-04$ & 0.0030293 & 0.00026685 \\
\hline Job.stability & -0.0849512 & $4.5964 \mathrm{e}-03$ & 0.0738493 & 0.00650541 \\
\hline Ownership & -0.0520347 & $2.8154 \mathrm{e}-03$ & 0.0452346 & 0.00398473 \\
\hline $\begin{array}{l}\text { Highest.level.of.education.of.family.me } \\
\text { mbers }\end{array}$ & -0.0158415 & $8.5713 \mathrm{e}-04$ & 0.0137712 & 0.00121311 \\
\hline
\end{tabular}

Source: calculation in this research

\section{Discussion}

Human capital is among the most important factors affecting on income and for cities with poor regions. The many of the urban poor are residing in informal settlements and city of Mashhad has most population located in informal settlements in Iran with about 1.2 million people. This study surveys the determinants of poverty in one of informal settlements of Mashhad in the name of Sheikh-Hasan. Among various variables impact on poverty level, Human capital has analyzed specially. For this purpose, first extreme, absolute and Relative poverty lines are measured and then ordered logistic regression used to investigate influence factors on poverty level. Dependent variable (poverty) including the four categories (Households with less than the minimum food needs, households below the absolute poverty line and above the minimum food needs, households below the relative poverty line and above the line of absolute poverty, and households above the relative poverty line.

Education level, experience and skill are the most important components of human capital and they affect poverty. According to the results, variables of "Education level" and "highest level of education of household members" have positive effect and significant on poverty, but experience and skill are not significant. Also, result shows that "age of head of household" and "job stability" have significant effect on poverty alleviation on poverty. Change in job status or job instability is one of the main problems in urban poor areas and Sheikh Hassan neighborhood. This instability leads to lack of skill and experience on the job. For this reason, residents of poor neighborhoods generally have very little experience and skills and thus effect of these variables on poverty are not significant. Education head of household directly affect job kind and skill and indirect effect on per-capita income households through a household size. Household size has a significant negative impact on the poverty and households with smaller size will be per capita income higher. According to data analysis, households with higher education have relatively smaller scale.

Calculation of marginal effects has shown that rising "education of household head" increases the chance switching household to the third and the fourth categories, respectively 3 and 0.26 percent. Also, the household chance for sit in the first category decreases 3.49 percent. Marginal effects represents education of household head has a dramatic impact on the level of poverty. So the households located on the first category to the third category (the households below the relative poverty line) have generally much lower education level compared to the fourth category (the households above the relative poverty line). As a result, target group to empower the poor in order to enhance the level of education of household head is third category (households above the absolute poverty line and below the relative poverty line). Comparison of marginal effects show that "Education of household head" has one of the greatest impacts on increasing welfare and reducing poverty levels household (impact coefficient). In general, human capital is among the most important policy factors in urban poverty alleviation in informal settlements of Mashhad.

By focusing on human capital, it can be suggested that increasing the level of knowledge for household heads and creation of favorable conditions for increasing the level of education of household members effective on income levels and thus reduce household poverty is very impressive. As a result, one of the most effective and the most important measures to reduce poverty in marginalized areas of the city of Mashhad is knowledge 
improvement in households, spatially household head.

\section{References}

Ali, S., \& Ahmad, N. (2013). Human Capital and Poverty in Pakistan: Evidence from the Punjab Province. European Journal of Science and Public Policy, 11, 36-41.

Bani-Fatemeh, H. (2012). Global city. Journal of Urban Sociological Studies, 2(3), 1-20.

Bohn Nielsen, H. (2005, Fall). Likelihood Analysis of Binary Choice Models. Econometrics, 2.

Dercon, S., \& Krishnan, P. (1998). Changes in Poverty in Rural Ethiopia 1989-1995: Measurement, Robustness Tests and Decomposition. Working paper, Centre for the study of African Economies, University of Oxford.

Handa, S., Simler, K., \& Harrower, S. (2004). Human Capital, Household Welfare, and Children's Schooling in Mozambique. (No. Research Report 134). Washington, D.C.: International Food Policy Resear ch Institute.

Heydari, M., \& Samy, A. (2012). The Estimate of the Minimum Required for Living Expenses (Poverty Line) Urban and Rural Households Khorasan Razavi Province Using the Habit Formation Linear Expenditure System. Quarterly Iranian Journal of Applied Economics, 3(10), 57-89.

Naghdi, A. (2010). Immigration and marginalization in Iran. Journal of Population, (73/74), 85-104.

Rashidi, P., \& Meidani, A. N. (2013). Evaluation of poverty in urban areas, Khorasan Razavi (1996-2012). Journal of Economics and Modeling, 4(14/15), 133-155.

Rolleston, C. (2009). Human Capital, Poverty, Educational Access and Exclusion: The Case of Ghana 1991-2006. Create Pathways to Access, Research Monograph, (22).

Salari, M. J. (2016). Comparison of poverty in the eastern provinces of Iran (1994-2014). Journal of New Ideas on Science and Technology, 1(1), 12-24.

Sarwar Awan, M., Iqbal, N., \& Waqas, M. (2011). The Impact of Human Capital onUrban Poverty: The Case of Sargodha City. journal of Sustainable Development, 4(1), 143-150. https://doi.org/10.5539/jsd.v4n1p143

Sharafat, A., \& Najid, A. (2013). Human Capital and Poverty in Pakistan: Evidence from the Punjab Province. European Journal of Science and Public Policy, 11, 36-41.

Statistical Yearbook of Education. (2015).

Statistical yearbook of the Mashhad. (2014).

Taghdisi, A., Jamini, D., \& Moradi, N. (2012). Investigation and Analysis of the Process of Employment and Unemployment in Sahneh Township during the Years of 1996-2006. Journal of spatial planing, 1(3), 81-105.

Ullah Iqbal, T., \& Rehman, Z. U. (2016). Impact of Human Capital on Poverty Alleviation in District Karak, Khyber Pakhtunkhwa. Dialogue (1819-6462), 11, 228-241.

\section{Notes}

Note 1. Mashhad is the center and capital of the Khorasan-Razavi province.

Note 2. The 48 neighborhoods are located in informal settlements of Mashhad.

Note 3. The literacy rate of Mashhad is 91 percent.

Note 4. Skilled workers who are that technical training have achieved in a teaching profession such as plasterers, welders, sewing, hairdressing, carpentry and other skills.

Note 5. Households with less than the minimum food needs (below the extreme poverty line), households below the absolute poverty line and above the extreme poverty line, households below the relative poverty line and above the line of absolute poverty, and households above the relative poverty line. 
